\title{
Maximizing Efficiency and Sustainability of Aquatic Food Production from Aquaponics Systems - A Critical Review of Challenges and Solution Options
}

\author{
Abentin Estim ${ }^{1}$, Sitti Raehanah M. Shaleh ${ }^{1}$, Rossita Shapawi ${ }^{1}$, Shafiqah Saufie ${ }^{1}$, \\ Saleem Mustafa ${ }^{1, *}$
}

${ }^{1}$ University Malaysia Sabah, Borneo Marine Research Institute, 88400 Kota Kinabalu, Sabah, Malaysia

\author{
Article History \\ Received 17 April 2020 \\ Accepted 05 June 2020 \\ First Online 08 June 2020

\section{Corresponding Author} \\ Tel.: +6088320000 \\ E-mail: saleem@ums.edu.my
}

\section{Keywords}

Ecological aquaculture

Aquaponics

Nutrient cascading

Biomass ratios

Sustainability

\begin{abstract}
Aquaponics is an emerging area of ecological aquaculture comprising diverse technologies that converge on integrating recirculating aquaculture and hydroponics in one production unit. It has made possible to simultaneously produce fish and vegetables with nutrient cascading and water conservation as among its core concepts. While production of these food items is the material output of the system, there is a complexity of processes involved which opens a vast scope for innovations. Production of fish and plants integrated in the aquaponics fluctuates depending on the various biodynamic links that influence the nutrient turnover and water quality across the unit. A successful operation of aquaponics production unit, therefore, requires a thorough understanding of the whole system as a functioning ecosystem comprising fish, plant and the nitrifying bacteria. These biological components differ in their optimum requirements but the overall homoeostasis of the composite system can be maintained through regulating the water quality and nutrient profiles by way of adaptive interventions for acceptable tradeoffs. Balancing of nutrients by appropriate rates of stocking of fed and extractor species, feeding based on nutrient composition and anticipated excreted nutrients are essential for sustainability of aquaponics. It deserves emphasis that with so many variables in the system, there is obviously a vast scope for unlimited diversification and innovations to improve the production efficiency and sustainability. Regions facing water stress or where conservation of water is a priority will particularly benefit from aquaponics.
\end{abstract}

\section{Introduction}

There is a growing interest in introducing the essential elements of circular economy to agriculture. This is emerging as a new discipline of aquaculture called as the 'Aquaponics' which combines growing fish in captivity on the pattern of recirculating aquaculture with the farming of plants in a soilless condition (hydroponics). The key considerations are minimizing waste and making the most efficient use of resources to maximize gains from the production system. The nutrient-rich water from the fish-holding area provides the natural manure for the plants, and the plants purify the water to a quality that is fit to be recycled to the fish holding area. The system operates in a closed loop where water and waste are recycled in such a way that the food production continues on a sustainable basis.

The aquaponics concept of recovering and regenerating products and materials based on 'ReduceReuse-Recycle' model differs from what is called the 'Take, Make, Dispose' model of production characterizing the traditional linear economy practices of the farming systems. Aquaponics is being applied to sustainably produce fish and vegetables in any weather condition, and is especially a more suitable option for regions facing the shortage of water. 
With the changing climate and increasing resource scarcities the traditional systems of aquaculture are becoming increasingly constrained. Aquaponics offers a good alternative that is more resilient and efficient. However, as with any new production system that is in its infancy, aquaponics faces many hurdles in its sustainable development. The challenges are linked to coupling of two technologies (recirculation aquaculture) and hydroponics (Konig et al., 2018) to ensure sustainability of an efficient integrated food production system. Nevertheless, it opens a new horizon for blended technological innovations focused at the interface between fish and plant production but without downsizing the not-so-visible but very active role of biological filters regulating the nitrogen cycle in the production unit. Storey (2016) has highlighted the scope of innovations that have sustained aquaponics and will shape its future growth trajectory. This is understandable given the fact that it is a new area of food system that has to grow under a diversity of conditions and a changing climate.

A review of recent publications reveals conflicting outcomes from aquaponics trials which could pose a setback to commercial-scale investment in this food production system. The present study was undertaken to address this problem through an in-depth analysis of the causes of differences in results and providing ideas that can ensure successful harvest from aquaponics. The most glaring aspect appears to be the mismatch between the biomass ratios of the captive fish and plants that impairs the nitrogen cycle in the system. These issues are elaborated here together with some smart options that provide the way forward.

\section{Materials and Methods}

This paper is based on an in-depth review of published data on aquaponics with the intention of critically examining the results of different experimental trials. In the process of extracting the required information this review has to confront the disparity in results emanating from differences in production designs, especially the areas where aquaponics was implemented, scale of operation, sources of water supply, types of integrated (fed and extractive) species and their stocking rates, and other variables that can influence the results. It has not been possible to investigate the differences in the data possibly linked to density of nitrifying bacteria due to a lack of microbiological studies on the bacterial enumeration in the aquaponics units. However, even though the overwhelming number of investigations is based on the presumed presence of nitrifying bacteria, a rationalization of the dynamics of nitrogen conversions in the nitrogen cycle was done to understand the differences in the aquaponics yields. This enabled the identification of causes and consequences of the factors, especially those pertaining to stocking rates of fed species (fish, crustacean) and extractive species (plant, seaweed), to complete the synthesis of information needed for generating this review.

\section{Major Components of Aquaponics and Their Operating Mechanisms}

There are three main biological components of aquaponics systems, namely fish, plant and nitrifying bacteria. They are held in a farming system that structurally comprises a Fish-Holding Chamber (FHC) that is connected to a water-inlet pipe and a waterdrainage pipe that takes the culture medium to the plant-chamber technically called as the 'Grow-Bed Area' (GBA). A pipe from the GBA drains the water into a sump from where it is diverted back to the FHC. This structural arrangement is shown in Figure 1.

Aquaponics systems are becoming diversified and differ in so many factors that generalizing the optimum parameters for holding multiple species in one farming unit poses difficulties. The word 'fish' here refers to any finfish or shellfish that represents the fed species which depends on the external feed input. The plant grown in the GBA is often referred to as the extractor species due to its capacity to extract nutrients for growth.

There are differences in the fed species, choice of plant species, designs, scale of operation, and the climatic conditions under which the aquaponics is carried out. Leaffin (2019) has emphasized the need to examine the effects of at least the key factors that include the stocking densities of fish and plant, feeding rate of fish and the system design to be able to optimize the total harvest of this integrated farming system.

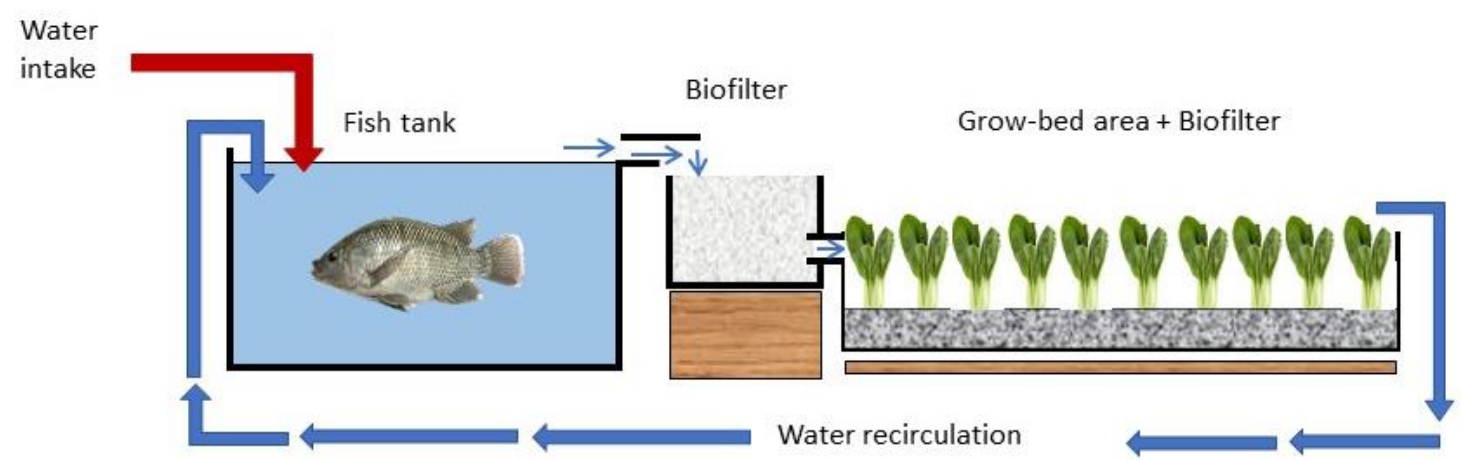

Figure 1. Layout of the aquaponics farming system. 


\section{Mechanism of Nutrient Cascading}

The only source of nutrients in the aquaponics system is the feed provided to the fish. The fish assimilates the required nutrients and excretes ammonia as the waste from protein digestion. The fish are known to use about $30 \%$ of the nitrogen contained in the feed (Rafiee and Saad, 2005) for their metabolic needs while excrete the rest through gills, urine and feces (Ru et al., 2017). The excreted nitrogen is in the form of Total Ammonia Nitrogen (TAN) that comprises the unionized ammonia $\left(\mathrm{NH}_{3}\right)$ and ionized ammonia $\left(\mathrm{NH}_{4}{ }^{+}\right)$. Both the $\mathrm{NH}_{3}$ and $\mathrm{NH}_{4}{ }^{+}$exist simultaneously in the water. The former can react with water to form the ionized ammonia.

The relative concentration of each or, in other words, the balance between $\mathrm{NH}_{3}$ and $\mathrm{NH}_{4}{ }^{+}$depends largely on $\mathrm{pH}$ and temperature. As the $\mathrm{pH}$ of water declines (i.e., the $\mathrm{H}^{+}$ion concentration increases), the free ammonia $\left(\mathrm{NH}_{3}\right)$ will tend to combine with $\mathrm{H}^{+}$, thereby shifting the chemical equilibrium towards the ionized $\left(\mathrm{NH}_{4}{ }^{+}\right)$state. On the contrary, as the $\mathrm{pH}$ increases the $\mathrm{NH}_{4}$ drops a proton $\left(\mathrm{H}^{+}\right)$to revert to $\mathrm{NH}_{3}$ form.

Nitrification is a 2-step process: Conversion of ammonia into nitrite and conversion of nitrite into nitrate (Figure 2). These processes are carried out by a group of chemolithotrophic and aerobic bacteria that derive energy by oxidizing inorganic nitrogen compounds. They are placed in two categories: Ammonia-Oxidizing Bacteria ( $A O B)$ that oxidize ammonia into nitrite, and the Nitrite-Oxidizing Bacteria (NOB) that oxidize nitrite into nitrate. The former category is also called as Nitrosomonas group that comprises Nitrosomonas, Nitrosospira, Nitrosococcus, Nitrosolobus and Nitrosovibrio, and the latter is named as Nitrobacter group that includes Nitrobacter, Nitrospina, Nitrococcus and Nitrospira). Nitrospira is known to be a complete nitrifier, i.e. it is involved in the production of both nitrite and nitrate (Daims et al., 2015). The rate of nitrification depends on ammonia, $\mathrm{pH}$, temperature and dissolved oxygen (Jukes and Cantor, 1969; Jones and Hood, 1980). Obviously, nitrification starts with the appearance of ammonia which serves as the food for the bacteria and follows the transformation pathway leading eventually to the formation of nitrate which is used by the plant for its growth. AOB start the colony formation within 5-7 days after the first addition of ammonia into the GBA and this triggers the ammonia-oxidation into nitrite (Somerville et al., 2014). By tracing the mechanism of nitrogen cycle in aquaponics, these authors documented that after another 5-7 days the nitrite concentration in the water starts to rise to a level that provides conditions for proliferation of NOB. This brings about the oxidization of nitrite into nitrate and a steady fall in the former- a necessary step to prevent toxicity in the GBA. Aquaponics systems that can ensure efficient partitioning of these nutrients for the three forms of life: fish, plant and nitrifying bacteria, meet the fundamental conditions for successful production and sustainability. In the water recirculation cycle of aquaponics, the successful completion of the cycle happens when the ammonia level is $<1 \mathrm{mg} /$ liter and nitrite is $0 \mathrm{mg} /$ liter (Somerville et al., 2014).

Due to toxicity of un-ionized ammonia $\left(\mathrm{NH}_{3}\right)$, its level can be minimized by reducing the $\mathrm{pH}$ to below 7.0, at which it gives way to the formation of less-toxic ammonium $\left(\mathrm{NH}_{4}{ }^{+}\right) . \mathrm{NH}_{3}$ is considered $300-400$ times more toxic to the fish than $\mathrm{NH}_{4}{ }^{+}$(Lemarie et al., 2004). Regardless of the lower toxicity of $\mathrm{NH}_{4}{ }^{+}$to the fish compared to $\mathrm{NH}_{3}$, it can also cause considerable stress when in concentration beyond the tolerance level. Working on Nile tilapia (Oreochromis niloticus), Da Silva et al. (2013) published data showing setback to the growth process resulting from $\mathrm{NH}_{4}{ }^{+}$stress. From a practical perspective it is, therefore, important to note that the harmless level of $\mathrm{NH}_{4}{ }^{+}$can be converted to

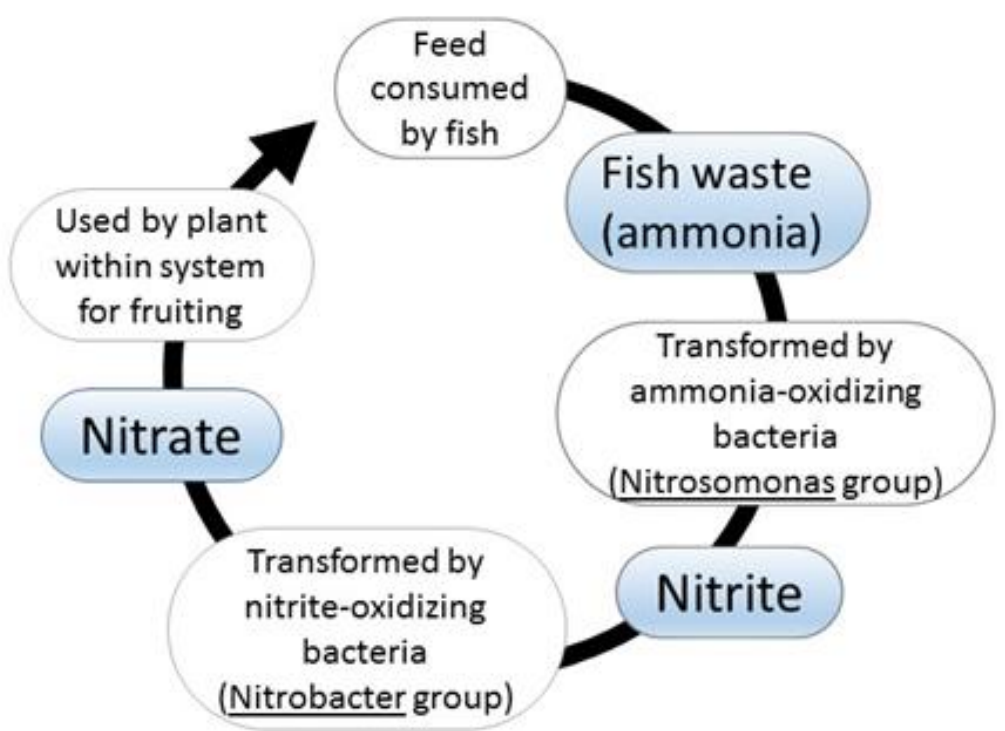

Figure 2. Process of nitrification in the aquaponics systems. 
harmful $\mathrm{NH}_{3}$ level when $\mathrm{pH}$ of the water increases. It is for this reason that the routine $\mathrm{pH}$ monitoring in the aquaponics system is necessary.

Qualitatively, composition of the supplied feed influences the chemical make-up of the waste generated in the $\mathrm{FHC}$ and chemical conditions in the various sections of the aquaponics unit. From a quantitative perspective, the size of the ration will matter in generation of the nutrient load, whether from the excreted metabolic waste or unused feed remains.

It is also possible to reduce ammonia by enhancing the nitrification efficiency. In fact, it is desirable to attempt the biofilration manipulation before changing the stocking rate of fish or and feed composition or ration size. There is no universally accepted standard for biomass ratios of fish and plant or the biofilter size. It depends on the metabolic processes of the fish and their nutritional requirements, and the biofiltration efficiency. However, there are general guidelines suggested by FAO (2015) for rationalizing the biomass ratios and other inputs in the aquaponics system around the proposed quantities (Table 1).

Robinson (2013) has rightly pointed out that 'rules of thumb' apply when it comes to deciding the stocking density due to the fact that the variables in the aquaponics have to be factored in choices about the fed species and their density in the holding area.

\section{System Biodynamics and Homoeostasis}

Aquaponics systems represent a high level of biodynamics due to multiple species, with each exerting effects on the chemical quality of water. Maintaining homoeostasis in such a production unit becomes difficult but is essential for it to be accepted as a near self-sustaining farming system which requires minimal input and mimics an ecological cycle. The system has to work towards a compromise between the fish, plant and nitrifying bacteria even as the bioengineering intervention seeks to optimize the quality of culture medium across the production module. It is sought to be achieved by ensuring the nutrient levels according to inherently different requirements of the biological entities as far as possible. This sort of compromise is possible if the variations in water quality are within the threshold limits of the organisms even though not strictly meeting the optimum values. What eventually matters is sustainability, and quality and quantity of the harvest. To elaborate this issue, let us consider a system where the fed species is the Nile tilapia (Oreochromis niloticus). This is the most widely selected species in the aquaponics system anywhere in the world where aquaculture is practiced. The fish adapts very well to tanks, can be stocked in high densities, has a remarkable tolerance to environmental fluctuations, grows rapidly (fingerling stocked at $50 \mathrm{~g}$ weight can reach harvestable size of $600 \mathrm{~g}$ in 6-9 months), has a low food conversion ratio and good dress out percentage ( $86 \%$ with head, $33 \%$ without head, 33\% fillet) (Leaffin, 2019) under flexible culture conditions.

Evidently, it is difficult to set one value for each water quality parameter that could be optimal for the fish, plant and the nitrifying bacteria. The challenge is to maintain the water quality parameters within the range of tolerance of all the species held in one production unit. They have different optimum water quality requirements but tradeoffs are acceptable if the variations do not cross the boundaries of tolerance of any of these species. For example, tilapia prefers temperature ranging from $27-29^{\circ} \mathrm{C}$ for maximum growth, plants grow best at $21.5-24^{\circ} \mathrm{C}$ and biofilters (nitrifying bacteria) perform actively at temperature in the range of $25-30^{\circ} \mathrm{C}$ (Sallenave, 2016). Likewise, the optimum $\mathrm{pH}$ values are 6.5-8 for tilapia, 5-7 for the plant and 7.5-8 for nitrifying bacteria. Aquaponics systems will have to work on the basis of a compromise between the water quality requirements of these three very different biological entities. It is possible to integrate all these species in a culture system with compensatory adjustments even if the water quality parameters are peripherally different for one of the three selected biological entities in the system. This shifts the focus on quality and quantity of production as the ultimate outcome of aquaponics whatever the compromises and tradeoffs happen in the integrated farming. There could be suboptimal production of fish or plant but the aim remains on optimization of the overall harvest. Of course, it implies the yield of selected plant and fish while biofiltration that facilitates the process can be targeted for manipulation for adaptive management of the production cycle. A review of published data reveals how the production goals have been achieved under a range of water quality conditions in aquaponics systems (Table 2).

Table 1. General guidelines for biomass rations and inputs in aquaponics systems (FAO, 2015)

\begin{tabular}{|c|c|c|c|c|c|c|c|}
\hline \multirow[t]{2}{*}{$\begin{array}{l}\text { Fish-holding } \\
\text { volume (liter) }\end{array}$} & \multirow[t]{2}{*}{$\begin{array}{l}\text { Maximum fish } \\
\text { biomass (Kg) }\end{array}$} & \multirow[t]{2}{*}{$\begin{array}{l}\text { Feeding } \\
\text { rate (g/day) }\end{array}$} & \multirow[t]{2}{*}{$\begin{array}{l}\text { Water pumping } \\
\text { rate (liter/hour) }\end{array}$} & \multirow{2}{*}{$\begin{array}{c}\text { Filter } \\
\text { volume } \\
\text { (litre) }\end{array}$} & \multicolumn{2}{|c|}{$\begin{array}{l}\text { Minimum volume of } \\
\text { biofilter media (litre) }\end{array}$} & \multirow{2}{*}{$\begin{array}{c}\text { Plant- } \\
\text { growing } \\
\text { area }(\mathrm{m} 2)\end{array}$} \\
\hline & & & & & Volcanic tuff & Bioballs & \\
\hline 200 & 5 & 50 & 800 & 20 & 50 & 25 & 1 \\
\hline 500 & 10 & 100 & 1200 & $20-50$ & 100 & 50 & 2 \\
\hline 1000 & 20 & 200 & 2000 & $100-200$ & 200 & 100 & 4 \\
\hline 1500 & 30 & 300 & 2500 & $200-300$ & 300 & 150 & 6 \\
\hline 2000 & 40 & 400 & 3200 & $300-400$ & 400 & 200 & 8 \\
\hline 3000 & 60 & 600 & 4500 & $400-500$ & 600 & 300 & 12 \\
\hline
\end{tabular}


There is no coherence in published data even for ammonia and nitrite levels that can make a real difference to sustainability of the production system (Table 3). For this reason, without field trials under local conditions there is a risk of breaching the tolerance level, especially regarding ammonia and nitrite even for the same species of fish.

In view of the pathways of nitrogen turnover in aquaponics, particularly the factors that bring about transformations, it is advisable to maintain Total Ammonia Nitrogen (TAN) at $<1.0 \mathrm{mg} /$ liter (Sallenave, 2016) and monitor the $\mathrm{pH}$ and temperature for corrective actions for preventing the formation of toxic unionized ammonia and nitrite beyond the permissible levels. A practical approach emphasized by Sallenave (2016) and Mustafa et al. (2019) is to use ammonia test kits to rapidly measure the concentration of this substance at any given time and multiply it by the multiplication factor given in Table 4 or closest to the water temperature and $\mathrm{pH}$, and then dividing by 100 . For example, a TAN of $5 \mathrm{mg} /$ liter at $\mathrm{pH} 9$ and temperature $20^{\circ} \mathrm{C}$ would be $5 \times 28.4 \div 100=1.42 \mathrm{mg} / \mathrm{liter}$ of unionized (toxic) ammonia.

\section{Production Efficiency}

In the aquaponics system the yield of fish and plants is the most visible output but the nitrifying bacteria play a vital role. Table 5 shows the efficiency of production of Nile tilapia in two different aquaponics systems. A key factor in successful aquaponics is the balance between the stocking rate of fish, biomass of plants and density of nitrifying bacteria (Somerville et al., 2014). The nitrifying bacteria carry out biological filtration- a general term referring to the process of using beneficial bacteria to improve the water quality at molecular level. A successful production will be possible if there is a proper balance in the internal environment (homeostasis) of the fish maintained by the excretory pathways, especially the kidney and the gills. It is, therefore, desirable to carry out preliminary experiments to adjust these ratios before starting the actual production. Factors that enhance the level of nitrogen entering the system include increase in the: stocking rate of fish, rate of feeding and protein content of the feed. If the biofiltration fails to deal with the ammonia load despite modifications in the biofilter size then downsizing these factors, either individually or collectively, is the available option. Among these interventions, the selection of the most appropriate one should be based on turnover of the nitrogenous products in the system. In order of priority these steps are: a) Reducing feed supply if that does not affect the fish growth, b) Providing feed with a lesser proportion of protein and c) Reducing the stocking density of the fish.

The nitrifying bacteria naturally develop in the system since they exist on land, in water and in the air (Somerville et al., 2014). However, their density can be increased by providing substrates that will help in colonization. These substrate structures together with their bacterial load form the biofilter. In functional terms, the biofilter size really means the bacterial density. Biofiltration efficiency depends on the biological surface area (BSA) which is the amount of

Table 2. Permissible water quality ranges for tilapia in aquaponics systems

\begin{tabular}{lcc}
\hline Parameters & Range of values & References \\
\hline Temperature, ${ }^{\circ} \mathrm{C}$ & $26-30$ & Cavalcante et al. (2014) \\
& $27-30$ & Leaffin (2019) \\
Dissolved oxygen, $\mathrm{mg} /$ liter & $>25$ & Lennard (2017) \\
& $\geq 3$ & Cavalcante et al. (2014) \\
$\mathrm{pH}$ & $>5$ & Timmons et al. (2002), Leaffin (2019) \\
& $6-9$ & Sekretariat-Nigara (2001) \\
& 7.5 & Goddek et al. (2016), Suhl et al. (2016) \\
TAN, mg/liter & $7-8$ & Leaffin (2019) \\
Unionized ammonia & $0.17-3.87$ & Caldini et al. (2015) \\
& $<0.04$ & Leaffin (2019) \\
Nitrite & $<0.02$ & Eck et al. (2019) \\
& $0.02-0.12$ & Sekretariat-Negara (2001), Cavalcante et al. (2014) \\
& $<0.8$ & Leaffin (2019) \\
Nitrate & $<0.5$ & Godfrey (2018) \\
& $<1.0$ & Losordo et al. (1998), Timmons and Ebeling (2013) \\
& $0.2-219$ & Caldini et al. (2015) \\
& $150-300$ & Goddek et al. (2015), Graber and Junge, 2009 \\
\hline
\end{tabular}

Table 3. Ammonia and Nitrite concentrations reported for Tilapia aquaponics system

\begin{tabular}{|c|c|c|c|}
\hline Toxic nitrogenous waste & Parker (2002) & Sallenave (2016) & Leaffin (2019) \\
\hline Ammonia, $\mathrm{NH}_{3}^{-}$(unionized), $\mathrm{mg} /$ liter & $<0.1$ & $<0.04$ & $<0.04$ \\
\hline Nitrite, $\mathrm{NO}_{2}-\mathrm{mg} /$ liter & $<0.4$ & $<1.0$ & $<0.8$ \\
\hline
\end{tabular}


surface on which the nitrifying bacteria can aggregate to perform their role. Selection of biofilter media offers perhaps the widest scope for innovations since there is no limit to the types of products that can be tested for their BSA. Many natural products (for example, coral rubble, rocks, sea shells, coconut coir, pine bark) as well as artificially constructed materials (examples, AquaMat, CrystalBio, geotextiles) have been examined. These types of biofilter substrates have pros and cons, and thus the need for tradeoffs. Preference of the media depends on the scale of advantages that can accrue from their use despite some of the attributes posing minor constraints. Main considerations include: cost, weight, density, water movement, surface features, operational convenience, underwater stability, ability to anchor plant roots and many others. However, BSA takes precedence over most of the substrate features. Storey (2016) has rightly termed it as the soul of a good aquaponics system and integral to the engines that drive the aquaponics. Even with these tradeoffs in water quality the systems of aquaponics have yielded $600 \mathrm{~g}$ of fish in 6-8 months (Somerville et al., 2014).

As far as the vegetable production is concerned, several authors working on aquaponics have measured different features of the plants to express their growth. This is unlike the rather straightforward assessment of the fish growth and production, and which makes comparison of data generated by different studies somewhat difficult. Aquaponics model presented by
Starthopoulou et al. (2018), as described above for tilapia growth, also contains data for the co-cultured basil plant (Ocimum basilicum) which suggested the total plant biomass and increase in height and growth rate to be $147.1 \pm 28.15 \mathrm{~g}, 45.7 \pm 12.42 \%$ and $0.2 \pm 0.06$, respectively. In the experiments conducted by Estim et al. (2019) the data on growth pertained to plant biomass, length of roots and pods of the green bean (Phaseolus vulgaris) whereas for the Chinese cabbage (Brassica rapa chinensis) the observations covered the growth of biomass and length of the roots. All these experiments have shown that the efficiency of nutrient cascading under aquaponics systems plays a key role in successful harvest of the plant crops as well as the fish.

Problems in aquaponics systems that often arise are generally linked to a disturbed balance in the dynamic equilibrium. Somerville et al. (2014) surveyed many such issues and identified causative factors. Any problem that arises in aquaponics should be addressed by finding the most appropriate solution without delay because the biodynamic processes can be rapid and their impairment lead to decline in production or even mortality of stocked species. In this connection, attention should be given to:

\section{Biomass Ratio (Stocking Rate of Fish and Plant)}

Problem- Nitrate accumulation in the system. Its solution will be increasing the plant stocking density.

Table 4. Percentage of total ammonia in un-ionized form at various temperature and $\mathrm{pH}$ values and temperature (adapted from Francis-Floyd et al., 2009)

\begin{tabular}{|c|c|c|c|c|c|c|c|c|}
\hline \multirow{2}{*}{$\mathrm{pH}$} & \multicolumn{8}{|c|}{ Temperature, ${ }^{\circ} \mathrm{C}$} \\
\hline & 20 & 21 & 22 & 24.5 & 26 & 28 & 30 & 32 \\
\hline 7 & 0.396 & 0.425 & 0.457 & 0.546 & 0.607 & 0.697 & 0.799 & 0.95 \\
\hline 7.2 & 0.625 & 0.673 & 0.723 & 0.863 & 0.958 & 1.10 & 1.25 & 1.25 \\
\hline 7.4 & 0.988 & 1.06 & 1.14 & 1.36 & 1.50 & 1.73 & 1.98 & 2.36 \\
\hline 7.6 & 1.56 & 1.67 & 1.80 & 2.14 & 2.36 & 2.72 & 3.11 & 3.11 \\
\hline 7.8 & 2.44 & 2.63 & 2.80 & 3.35 & 3.68 & 4.24 & 4.84 & 4.84 \\
\hline 8.0 & 3.82 & 4.10 & 4.39 & 5.21 & 5.75 & 6.56 & 7.46 & 8.77 \\
\hline 8.2 & 5.92 & 6.34 & 6.79 & 8.01 & 8.75 & 10.0 & 11.3 & 13.2 \\
\hline 8.4 & 9.07 & 9.69 & 10.3 & 12.1 & 13.0 & 15.0 & 16.8 & 19.5 \\
\hline 8.6 & 13.7 & 14.5 & 15.5 & 17.9 & 19.4 & 21.8 & 24.3 & 27.7 \\
\hline 8.8 & 20.0 & 21.2 & 22.5 & 25.7 & 27.8 & 30.7 & 33.7 & 37.8 \\
\hline 9.0 & 28.4 & 29.9 & 31.5 & 35.5 & 37.7 & 41.2 & 44.6 & 49.0 \\
\hline 9.2 & 38.6 & 40.4 & 42.1 & 46.5 & 49.2 & 63.8 & 56.1 & 70.8 \\
\hline 9.4 & 49.9 & 51.8 & 53.5 & 58.0 & 60.5 & 63.8 & 66.9 & 70.7 \\
\hline 9.6 & 61.3 & 63.0 & 64.6 & 68.5 & 70.8 & 73.6 & 76.2 & 85.9 \\
\hline 9.8 & 71.6 & 72.9 & 74.3 & 77.6 & 79.4 & 81.6 & 83.6 & 85.9 \\
\hline 10.0 & 79.9 & 81.0 & 82.1 & 84.5 & 85.9 & 87.5 & 89.0 & 90.6 \\
\hline
\end{tabular}

Table 5. Production efficiency of tilapia in two different aquaponics systems

\begin{tabular}{lcc}
\hline Parameters & Stathopoulou et al. (2018) & Estim et al. (2019) \\
\hline Temperature, ${ }^{\circ} \mathrm{C}$ & $25.7 \pm 0.8$ & $25.2 \pm 0.25$ \\
Dissolved oxygen, mg/liter & $7.0 \pm 0.2$ & $6.6 \pm 0.13$ \\
$\mathrm{pH}$ & $7.1 \pm 0.4$ & $7.14 \pm 0.06$ \\
$\mathrm{NH}_{3}{ }^{-}$ & $0.78 \pm 0.83$ & $0.23 \pm 0.02$ \\
$\mathrm{NO}_{2}{ }^{-}$ & $0.82 \pm 0.13$ & $0.39 \pm 0.22$ \\
Specific growth rate of tilapia, \%day ${ }^{-1}$ & $1.8 \pm 0.17$ & $2.7 \pm 0.04$ \\
\hline
\end{tabular}


Problem- Nitrate deficiency in the system. Solution to this problem will be reducing plant biomass in proportion to fish stocking density.

\section{Heath Condition of the Plant}

Problem- Symptoms of nutritional deficiencies manifesting in growth retardation, poor root development, fading of green color of leaves and even yellowing. Solutions include increase in fish biomass, increase in ration size, enhancing biofiltration and reducing plant biomass.

\section{Health Condition of the Fish}

Problems - Stress in the captive stock as evident from increased rate of surfacing or gasping, rubbing against tank wall, sluggishness, decline in growth, increase in mortality rate, red dots or patches around fins and eyes. There is a range of solutions that comprise increasing biofiltration to work on nitrogenous waste, especially ammonia and nitrite. A more comprehensive investigation will be required to determine the causes by analyzing water quality in each of the components of the aquaponics system.

System malfunctioning: Leakage of water supply pipes and holding tanks, aeration, light and pumping. These are visible problems, requiring repairing.

\section{Conclusions}

In view of the fact that aquaponics systems work on the principle of minimizing material inputs while reusing the water and nutrients, they offer a viable solution for sustainable production of fish as well as plants. Because, it is a new aquaculture production method, more research and developments are needed to address the challenges for better efficiency and sustainability. In this context, the topic of priority includes quantitative research to support the development of practically feasible and economically viable aquaponics models. Although there is a growing number of studies on the scientific aspects and module designs, but the commercial feasibility has not received the attention it deserves. To make aquaponics economically attracting to entrepreneurs the key consideration would be the profitability that will accrue from a healthy growth of fish and the plant in a shorter period of time. Scientific trials on optimizing growth of the two integrated species that demonstrates the commercial viability together with other elements of sustainability will make a significant difference to commercialization of this aquatic food production sector. Of course, water quality dynamics across the production unit is a prerequisite for successful outcome from aquaponics. If this requires a structural design modification that envisages multi-loop decoupled arrangements for independent recirculating loops for fish and plants, and may be for metabolic waste neutralization, through independent recirculating loops, trials will have to be carried out for confirming the sustainability in all its dimensions. This is a topic that can be pursued focusing on nutrient recovery and their bioavailability for the selected species of fish and plants. Again, since profitability in addition to operational convenience, will influence the commercial-scale adoption of aquaponics, it is pertinent to invest more research efforts in multi-loop designs of aquaponic systems and to quantitatively evaluate the gains in terms of production efficiency (economic aspect), nutrient cascading and water conservation (environmental compatibility) and harvest quality (consumer interest).In the aquaponics system, $\mathrm{pH}$ stabilization is of paramount importance for fish, plant and nitrifying bacteria. While some trade-off can occur but it should remain within the range of tolerance of all these three biological entities. This will facilitate better growth performance of the fish, efficient nutrient uptake by plants, and effective nitrification by the nitrifying bacteria. The values for fish and plant will depend on the selected species and, therefore, preliminary trials are necessary to establish the standard conditions to be followed throughout the production cycle, leading to the stage of harvesting. Coupling of technologies and approaches in aquaponics opens up a vast horizon for innovations that could be 'disruptive' in terms of positive outcomes arising out of the departure from conventional practices. A profitable aquaponics provides a practical model that demonstrates successful integration of a circular economy approach in the realm of agriculture. The aquatic farming sector can achieve greater sustainability by reduced inputs and retaining more resources in the production loops. By economizing production and feasibility of operation in widely different geographical regions and socio-economic conditions, such a circular economy model of food production can shape our pathway towards a more dependable farming system and a sustainable future.

\section{Acknowledgements}

This research was supported by grants from the Ministry of Higher Education of Malaysia (NRGS0001) and Universiti Malaysia Sabah (Niche Grant Scheme, SDN0022-2019).

\section{References}

Caldini, N.N., Cavalcante, D.D.H., Filho, P.R.N.R. et al. (2015). Feeding Nile Tilapia with artificial diet and dried bioflocs biomass. Acta Scientarium (Animal Sciences) 37, 335 341.

Cavalcante, D.D.H., Caldini, N.N., Da Silva, J.L.S., Lima, F.R.D.S. et al. (2014). Imbalance in the hardness/ alkalinity ratio of water and Nile tilapia's growth performance. Acta Scientiarum-Technology 36, $49-54$. 
Da Silva, F.J.R., Lima, F.R.S., do Vale, D.A. et al. (2013). High levels of ammonia nitrogen as $\mathrm{NH}_{4}^{+}$are stressful and harmful to the growth of Nile tilapia juveniles. Acta Scientiarum 35 (4), 475-481.

Daims, H., Lebedeva, E.V., Pjevac P, Han, P. et al. (2015). Complete nitrification by Nitrospira bacteria. Nature 528, 504

Eck, M., Körner, O. \& Jijakli, M.H. (2019). Nutrient Cycling in Aquaponics Systems. In: Goddek S., Joyce A., Kotzen B., Burnell G. (eds), Aquaponics Food Production Systems. Springer, Cham, Switzerland.

Estim, A., Saufie, S. \& Mustafa, S. (2019). Water quality remediation using aquaponics sub-systems as biological and mechanical filters in aquaculture. Journal of Water Process Engineering 30. DOI:org/10.1016/j.jwpe.2018.02.001.

FAO (2015). Management of the Aquaponics Systems. Food and Agriculture Organization of the United Nations, Rome, Italy.

Francis-Floyd, R., Watson, C., Petty, D. et al. (2009). Ammonia in aquatic systems. University of Florida, Gainesville, USA.

Goddek, S., Delaide, B., Mankasingh, U. et al. (2015). Challenges of sustainable and commercial aquaponics. Sustainability 7, $4199-4224$

Goddek, S., Espinal, C.A., Delaide, B., Jikali, M.H. et al. (2016). Navigating towards decoupled aquaponics systems: a system dynamics design approach. Water 8, 1- 29.

Godfrey, M. (2018). The quick reference guide for aquaponics farmers. Upstart University, Wyoming, USA.

Graber, A. \& Junge, R. (2009). Aquaponic systems: nutrient recycling from fish wastewater by vegetable production. Desalination 246, $147-156$.

Jones, R. D. \& Hood, M. A. (1980). Effects of temperature, pH, salinity, and inorganic nitrogen on the rate of ammonium oxidation by nitrifiers isolated from wetland environments. Microbial Ecology 6, 339-347.

Jukes, T. H. \& Cantor, C. R. (1969). Evolution of protein molecules, in: Munro, H. N. (Ed.), Mammalian Protein Metabolism. Academic Press, New York, pp. 21-132.

Konig, B., Janker, T., Reinhart, T. \& Villarroel, M. (2018). Analysis of aquaponics as an emerging technological innovation system. Journal of Cleaner Production 180, 232-243.

Leaffin (2019). Aquaponics - How Many Plants Per Fish? Leaffin. Com., San Diego, California.

Lemarie, G., Dosdat, A., Coves, D. et al. (2004). Effect of chronic ammonia exposure on growth of European seabass (Dicentrarchus labrax) juveniles. Aquaculture 229, 479491.
Lennard, W. (2017). Commercial Aquaponics Systems Integrating Recirculating Fish Culture with Hydroponic Plant Production. Wilson-Lennard, Victoria, Australia.

Losordo, T.M., Masser, M.P. \& Rakocy, J.M. (1998). Recirculating Aquaculture Tank Production Systems: An Overview of Critical Considerations. SRAC Publication 451, USA.

Mustafa, S., Estim, A. \& Saufi, S. (2019). Biodynamics in integrated aquaculture systems and challenges in producing organic food using low-carbon methods. Borneo Journal of Marine Science \& Aquaculture 3 (1), 1 8.

Parker, R. (2002). Aquaculture Science. Delmar, Albany, USA.

Rafiee, G. \& Saad, C.R. (2005). Nutrient cycle and sludge production during different stages of red tilapia (Oreochromis sp.) grown in a recirculating aquaculture system. Aquaculture 244, 109- 118

Robinson, N. (2013). Aquaponics Stocking Density. Bright Agrotech. ZipGrow, Ontario, Canada.

Ru, D., Liu, J., Hu, Z., Zou, Y. et al. (2017). Improvement of aquaponics performance through micro- and macronutrient addition. Environmental Science and Pollution Research 24, $16328-16335$.

Sallenave, R. (2016). Important Water Quality Parameters in Aquaponics Systems. Circular 680, New Mexico State University, New Mexico, USA.

Sekretariat-Negara (2001). Water Quality Management and Water Pollution Protection. Report no. 82, Government Regulation, Indonesia, Jakarta.

Somerville, C., Cohen, M., Pantanella, E., Stankus, A. et al. (2014). Small-scale Aquaponics Food Production: Integrated Fish and Plant Farming. Technical Paper 589, Food and Agriculture Organization, Rome, Italy.

Stathopoulou, P., Berillis, P., Levizou, E., SakellariouMakrantonaki, M. et al. (2018). Basil and Nile tilapia production in a small-scale aquaponics system. Journal of Fisheries Science.com 12 (4), 001-003.

Storey, A. (2016). Aquaponic Media: The Surface Area Problem and How to Solve It. Upstart University, Wyoming, USA.

Suhl, J., Dannehl, D., Kloas, W. et al. (2016). Advanced aquaponics: evaluation of intensive tomato production in aquaponics versus conventional hydroponics. Agricultural Water Management 178, 335 - 344.

Timmons, M.B. \& Ebeling, J.M. (2013). Recirculating Aquaculture. Ithaca Publishing, New York, USA.

Timmons, M.B., Ebeling, J.M., Wheaton, F.W., Summerfelt, S.T. et al. (2002). Recirculating Aquaculture Systems. Cayuga Aqua-Ventures, Ithaca, USA. 